CHAPTER 6

\title{
The Causes of Our Belief in Free Will: Spinoza on Necessary, "Innate," yet False Cognition
}

\author{
Yitzhak Y. Melamed
}

\section{Introduction $^{\mathrm{I}}$}

Spinoza defines freedom at the very opening of the Ethics. Thus, the seventh definition of Part I of the book reads:

That thing is called free which exists from the necessity of its nature alone, and is determined to act by itself alone. But a thing is called necessary, or rather compelled, which is determined by another to exist and to produce an effect in a certain and determinate manner [Ea res libera dicitur, quae ex sola suae naturae necessitate existit, et a se sola ad agendum determinatur; necessaria autem, vel potius coacta, quae ab alio determinatur ad existendum, et operandum certa, ac determinata ratione]. (EId7)

The pithy formulation of this definition makes clear that, for Spinoza, freedom is opposed not to necessity, ${ }^{2}$ but to compulsion. ${ }^{3}$ After explicating the key ontological implications of the definitions and axioms of Part I, Spinoza returns to the issue of freedom in ErpI7 - "God acts from the laws of his nature alone, and is compelled by no one" - from which he infers the corollary:

\footnotetext{
' Unless otherwise marked, all quotes of Spinoza's texts are from Curley's translation: The Collected Works of Spinoza. 2 vols. I would like to thank Ed Curley for generously providing me with drafts of volume two before its publication. I have relied on Gebhardt's critical edition (Spinoza Opera, 4 volumes) for the Latin text of Spinoza. I would like to thank Michael Della Rocca, Zach Gartenberg, John Heil, Chip Manekin, Zoran Vukadinovic, and especially, John Morrison, for their most helpful comments on earlier drafts of this chapter. An early version of this chapter has been read at the colloquium of the Philosophy Department at the Hebrew University of Jerusalem. I am indebted to the participants of that session for their critical comments.

2 Thus, Spinoza's notion of freedom - as defined in EId7 - is not only compatible with necessitarianism, but in fact consists in existing and acting "from the necessity of [one's] nature alone." Yet, necessitarianism, for Spinoza, is incompatible with the (Cartesian) notion of free will, and it is equally incompatible with the notion of moral desert.

3 Oddly enough, in E4p49d (which cites EId7), Spinoza contrasts freedom with necessity rather than compulsion. I suspect this might be residual from an earlier draft of the Ethics.
} 
It follows, secondly, that God alone is a free cause. For God alone exists only from the necessity of his nature (by PII and PI4CI), and acts from the necessity of his nature (by $\mathrm{P}_{7}$ ). Therefore (by $\mathrm{D}_{7}$ ) God alone is a free cause, q.e.d. (Eipı7c2. Italics added.) ${ }^{4}$

At this point, the reader clearly may anticipate Spinoza's uncompromising position on the issue of free will. Spinoza postpones his extensive attack on the Cartesian notion of free will until the final two propositions of Part II of the Ethics (E2pp48-49), since this offensive relies on an equally vehement anti-Cartesian conception of the nature of the human mind, and thus requires the demonstration of the propositions of Part II. Still, on several earlier occasions in the book - even in Part I that is not supposed to discuss the nature of the human mind - Spinoza cannot stop himself from noting the absurdity of the notion of free will. Thus, the topics of divine freedom (Erpi7s), necessitarianism (Erpp32-33), and Spinoza's critique of teleology (Erapp) give Spinoza occasion to begin expanding his sharp critique of freedom of the will, even before we enter Part II of the book, which is dedicated to the study of the nature of the human mind, and which is the proper place for the discussion of the freedom of the human will.

This chapter will discuss Spinoza's critique of free will, though our brief study of this topic in the first part of this chapter will aim primarily at preparing us to address the main topic of this chapter, which is Spinoza's explanation of the reasons that force us to believe in free will. ${ }^{5}$ At times, Spinoza seems to come very close to asserting the paradoxical claim that we are not free to avoid belief in free will. In the second part of this chapter, I will closely examine Spinoza's etiological explanation of how we come to form the belief in free will. In the third part, I will raise and respond to a crucial objection to Spinoza's explanation of the formation of our belief in free will. I will then turn to examine Fichte's intriguing claim that Spinoza's position on the issue of free will suffers from an internal contradiction, as evinced in Fichte's suggestive remark: "Spinoza could not have been convinced of his own philosophy. He could only have thought of it; he

\footnotetext{
${ }^{4}$ Notice again that God's being a free cause consists in nothing other than the fact that God exists and acts "only from the necessity of his nature." In other words, for Spinoza, freedom just is a certain kind of necessity (i.e., necessitation from one's nature alone). In his Freedom and Belief, Galen Strawson notes: "Not even God could be truly self-determining as to the motives for action; nor therefore could he be truly responsible for what he did in any ultimate way" (58). Spinoza would clearly accept Strawson's second claim while rejecting the first.

5 I will not address here several important features of Spinoza's discussion of free will, such as the question of the compatibility of determinism and moral responsibility. For an interesting contextualization of the latter issue, see Manekin, "Spinoza and the Deterministic Tradition."
} 
could not have believed it [Er konnte seine Philosphie nur denken, nicht sie glauben]."6

\section{Part I: Spinoza's Critique of Free Will}

Spinoza's reasons for rejecting the freedom of the will are pretty straightforward. His strict necessitarianism and determinism ${ }^{7}$ leave no place for any feature of the world that is not fully necessitated by what follows from God's nature or essence (which is itself necessary ${ }^{8}$ ). Thus, in Eip28 Spinoza proves that every finite thing

can neither exist nor be determined to produce an effect unless it is determined to exist and produce an effect by another cause, which is also finite and has a determinate existence; and again, this cause also can neither exist nor be determined to produce an effect unless it is determined to exist and produce an effect by another, which is also finite and has a determinate existence, and so on, to infinity.

Following the affirmation of strict determinism with regards to finite things in EIp28, Spinoza turns to proving shortly afterward that the will - even the divine will (a topic that is proper to Part I) - cannot be free.

EIp32: The will cannot be called a free cause, but only a necessary one.

${ }^{6}$ Fichte, Fichtes Werke, I 513|; Fichte, Introductions, 98. Cf. Wood, "Fichte on Freedom,” I32.

7 By necessitarianism I understand the view that no feature of the world could be otherwise than it is. An alternative formulation states that "whatever is possible, is necessary." By determinism I understand the claim that "every event is necessitated by antecedent events and conditions together with the laws of nature" (Hoefer, "Causal Determinism"). Obviously, one can adhere to determinism while rejecting necessitarianism, if one allows for two (or more) distinct possible worlds that are (each) thoroughly deterministic. It seems that, in principle, one may also assert necessitarianism while rejecting determinism. Thus, one may hold that there is only one possible world, $\mathrm{W}_{\mathrm{I}}$, and that this possible world contains at least one event that is not necessitated by antecedent events, but is rather self-necessitated (or is necessitated by virtue of certain features of the world, other than the antecedent events and the laws of nature). Some philosophers consider necessitarianism as a claim that is stronger than determinism (see Della Rocca, Spinoza, 75). I take the two claims as orthogonal. The main texts for Spinoza's determinism are Eıa3, Eıp27, and Erp28 (the latter text is discussed briefly later). The main text for Spinoza's necessitarianism is Eipi6 and its demonstration. Eipi6 asserts that God's nature or essence is necessary (perhaps implicitly relying on Edi). In Eipi6d, Spinoza demonstrates that everything that is, follows necessarily from God's essence. Thus, the combination of Eipi6 and its demonstration yields strict necessitarianism. Sleight, Chapelle, and Della Rocca rightly note that determinism plays a far more substantial role than necessitarianism in motivating Spinoza's critique of free will (see their "Determinism and Human Freedom," I227). John Morrison rightly pointed out to me that for Spinoza, necessitarianism and determinism stem from the same line of reasoning.

8 See the crucial formulation of Erpi6: "From the necessity of the divine nature" etc. Italics added. For a very useful discussion of Spinoza's necessitarianism, see Garrett, "Spinoza’s Necessitarianism." 
Dem.: The will, like the intellect, is only a certain mode of thinking. And so (by $\mathrm{P} 28$ ) each volition can neither exist nor be determined to produce an effect unless it is determined by another cause, and this cause again by another, and so on, to infinity. Even if the will be supposed to be infinite, it must still be determined to exist and produce an effect by God, not insofar as he is an absolutely infinite substance, but insofar as he has an attribute that expresses the infinite and eternal essence of thought (by P23). So in whatever way it is conceived, whether as finite or as infinite, it requires a cause by which it is determined to exist and produce an effect. And so (by $\mathrm{D}_{7}$ ) it cannot be called a free cause, but only a necessary or compelled one, q.e.d.

Cor. I: From this it follows, first, that God does not produce any effect by freedom of the will (italics added).

The first half of the demonstration addresses volitions as finite beings that thus fall under the scope of EIp28 and as such must be fully determined by their causes. Thus, a volition qua finite being is not "determined by its nature alone" (EId7), i.e., it is not free. In the second half of the demonstration (beginning with "Even if the will be supposed to be infinite"), Spinoza considers the possibility that a will (specifically, God's will) might be an infinite mode (an intriguing category that Spinoza introduces and discusses in Eipp2I-23 ${ }^{9}$ ). In Eipp2I-23 Spinoza proves that the infinite modes of each attribute follow necessarily from their cause: the "absolute nature" of a given attribute. ${ }^{\text {IO }}$ Thus, the will, whether it is a finite or infinite mode, must follow necessarily from its causes (and not from the will's "nature alone"). This allows Spinoza to establish in EIp32cI that "God does not produce any effect by freedom of the will."

In Eip33, Spinoza presents and demonstrates his most general formulation of necessitarianism.

EIp33: Things could have been produced by God in no other way, and in no other order than they have been produced.

Dem.: For all things have necessarily followed from God's given nature (by Pi6), and have been determined from the necessity of God's nature to exist and produce an effect in a certain way (by P29). Therefore, if things could have been of another nature, or could

9 For a detailed discussion of the infinite modes and their role in Spinoza's system, see my Spinoza's Metaphysics, chapter 4 .

Io See specifically Eip2Id (II/65/28), where the possibility that an infinite mode of thought ("God's idea") "does not follow necessarily from the nature [of thought] insofar as it is absolute thought" is presented as yielding a contradiction. 
have been determined to produce an effect in another way, so that the order of Nature was different, then God's nature could also have been other than it is now, and therefore (by PII) that [other nature] would also have had to exist, and consequently, there could have been two or more Gods, which is absurd (by PI4CI). So things could have been produced in no other way and no other order, etc., q.e.d.

The crux of Spinoza's argument here is simple.

(I) All features of the world follow necessarily from God's essence or nature (premise proven earlier in Eıpı6).

(2) Suppose that one of the features of the world (e.g., the color of the shortest black hair on my head) were other than how it actually is (e.g., if it were white or gray).

(3) God's nature would have to be different (from (I) and (2)).

Spinoza then goes on to infer from (3) that there would have to be two or more Gods (one with a nature that necessitates my having a black hair, the other with a nature necessitating my having a white or gray hair). Having more than one God (i.e., an absolutely infinite substance) contradicts Eipi4 ("Except God, no substance can be or be conceived"), and thus Spinoza concludes that (2) leads to absurdity. For our purposes Spinoza's inference to (3) is the most interesting. Spinoza treats the necessary causal flow from God's essence, or nature, to all things as a logical inference, and then infers (3) from (I) and (2) by modus tolens.

For the sake of concision I will skip over several other passages in Parts I and II where Spinoza presents arguments against the freedom of the will or claims that immediately imply the rejection of the will's freedom, ${ }^{\mathrm{II}}$ and turn straight to his main discussion of the issue at the very end of Part II of the Ethics.

E2p48: In the Mind there is no absolute, or free, will, but the Mind is determined to will this or that by a cause which is also determined by another, and this again by another, and so to infinity [In Mente nulla est absoluta, sive libera voluntas; sed Mens ad hoc, vel illud volendum determinatur a causa, quae etiam ab alia determinata est, et haec iterum ab alia, et sic in infinitum.].

Dem.: The Mind is a certain and determinate mode of thinking (by PII), and so (by IPI7C2) cannot be a free cause of its own actions, or cannot have an absolute faculty of willing and not willing. Rather, it must be

II See, e.g., Erp8s2 (II/5I/I-7), Eipırd (II/53/7-I4), Eip29, Eiapp (II/77/24-27), and E2p35s. 
determined to willing this or that (by $\mathrm{IP} 28$ ) by a cause which is also determined by another, and this cause again by another, etc., q.e.d.

Spinoza's argument in E2p48 is pretty simple.

(I) The mind is a finite mode of the attribute of thought (premise, proven in $\mathrm{E}_{2 \mathrm{pII}}{ }^{\mathrm{I}}$ ).

(2) "God alone is a free cause. For God alone exists from the necessity of his nature" (premise, proven in EIpI7c2).

(3) The mind is not a free cause (from (I) and (2)).

If we add the trivial premise, (2.5) "God, the absolutely infinite substance is not identical with any mode" - which Spinoza undoubtedly accepts - the foregoing inference is valid.

Notice that in this inference Spinoza proves that the human mind is not free in Spinoza's sense of freedom, as defined in EId7 (i.e., existing and acting from the necessity of one's own nature). The notion of freedom as uncaused is not addressed in the previous argument. The possibility of the will as an uncaused cause has been ruled out by various earlier propositions in the Ethics. Still, perhaps in order to address this worry, E2p48d continues by referring the reader to EIp28, which, as we have already seen, asserts strict determinism, and thus rules out the possibility of the mind's acting as an uncaused cause.

Spinoza's critique of the Cartesian notion of the will does not stop with the rejection of free will. ${ }^{\mathrm{I}}$ Pace Descartes, Spinoza argues that "the will" is not a faculty at all. ${ }^{\mathrm{I}}$ There is no will beyond the specific volition that occurs in the mind, just as there is no stone-ness over and above the existence of specific stones (E2p48s). Thus, our casual talk about "the will” is just an instance of our tendency for reification. In a further blow targeting Descartes' assertion that the will and intellect are distinct faculties, ${ }^{15}$ Spinoza will prove that volitions have no existence independently of the ideas that they affirm or deny (E2p49s). ${ }^{16}$ The six-page-long

I2 E2pII: "The first thing that constitutes the actual being of a human Mind is nothing but the idea of a singular thing which actually exists." Since, per E2d7, a "singular thing" is a finite mode, the idea of a singular thing must itself be a finite mode.

${ }^{13}$ For Descartes' affirmation of free will, see among other texts Meditation Four (AT VII 57 | CSM II 40), Second Set of Replies (AT VII I66 | CSM II II6), and Passions of the Soul, I \$4I (AT XI 359 | CSM I 343).

${ }^{\text {I4 }}$ For Descartes' view of the will as the "faculty of choice," see the Fourth Meditation (AT VII 56 | CSM II 39).

is See Descartes' Fourth Meditation (AT VII 57 | CSM II 40).

I6 See Della Rocca's excellent discussion of this issue in "The Power of an Idea," 205-212. 
scholium to E2p49 that concludes Part II of the Ethics is a concise tract on the issue of the freedom of the will. In this text, Spinoza addresses and refutes various arguments that attempt to establish the freedom of the will (including some arguments Spinoza himself employed for that purpose in his earliest works ${ }^{17}$ ).

\section{Part II: Why Do We Believe in Free Will?}

So far we have briefly discussed Spinoza's reasons for rejecting the freedom of the will. Yet the most interesting and least observed feature of Spinoza's discussion of the freedom of the will is his detailed, elegant, and incisive analysis of how we come to form the - false - belief in free will. Spinoza first presents a concise version of his analysis of the formation of our belief in free will in the appendix to Part I of the Ethics. The appendix is a polemical unit that aims primarily at refuting the belief in teleology. Spinoza takes teleology to be the result of a pile of errors, ${ }^{18}$ and therefore a full explanation of how we come to form the belief in teleology requires a careful excavation of the layers of error that eventually lead us to believe in final causes. The very first layer of error is the belief in free will.

After listing some of the prejudices resulting from the belief in teleology, Spinoza notes:

Of course this is not the place to deduce these things from the nature of the human mind. It will be sufficient here if I take as a foundation what everyone must acknowledge: that all men are born ignorant of the causes of things, and that they all want to seek their own advantage, and are conscious of this appetite.

From these [assumptions] it follows, first, that men think themselves free, because they are conscious of their volitions and their appetite, and do not think, even in their dreams, of the causes by which they are disposed to wanting and willing, because they are ignorant of [those causes]. (Eıapp | II/78/ı2-2I. Italics added.)

${ }^{17}$ Compare Spinoza's discussion of Buridan's Ass in E2p49s (II/I35/24-3I) with the discussion of the same issue in the early Cogitata Metaphysica (II I2 | I/277/32). In the Cogitata Metaphysica, Spinoza explicitly endorses Descartes' defense of free will in the Fourth Meditation and argues that insofar as freedom is part of the essence of the human soul, it cannot be fully compelled by external things, since nothing has the power of destroying its essence (II I2 | I/278/IO).

I8 The belief in divine teleology relies, among others, on the erroneous belief in human teleology. The belief in human teleology relies on the belief in free will, though the issue requires detailed elaboration that cannot be carried out here. 
The three elements that conspire to generate the belief in free will are: (I) our appetites and volitions, ${ }^{19}$ (2) our consciousness of our appetites and volitions, and, finally, (3) our general ignorance of the causes of most things, and specifically our ignorance of the causes that shape our volitions and appetites. ${ }^{20}$ Shortly, I will turn to showing that for Spinoza, each of these three elements is a necessary condition and that they are jointly sufficient for the formation of the belief in free will. But before we turn to that task, let us look briefly at another text where Spinoza provides a similar analysis yet advances one step forward in explaining why we conjure up a faculty of free will. The context of the discussion is Spinoza's more general claim that error and falsity consist in privation of knowledge. To illustrate this claim Spinoza provides two examples, the first of which is our belief in the freedom of the will.

In PI7S I explained how error consists in the privation of knowledge. But to explain the matter more fully, I shall give [NS: one or two examples]: men are deceived in that they think themselves free [NS: i.e., they think that, of their own free will, they can either do a thing or forbear doing it], an opinion which consists only in this, that they are conscious of their actions and ignorant of the causes by which they are determined. This, then, is their idea of freedomthat they do not know any cause of their actions. They say, of course, that human actions depend on the will, but these are only words for which they have no idea. ${ }^{2 \mathrm{I}}$ For all are ignorant of what the will is, and how it moves the Body; those who boast of something else, who feign seats and dwelling places of the soul, usually provoke either ridicule or disgust. (E2p35s. Italics added.)

19 For the distinction between will [voluntas], appetite [appetitus], and desire [cupiditas], see E3p9s: "When this striving is related only to the Mind, it is called Will; but when it is related to the Mind and Body together, it is called Appetite. ... Between appetite and desire there is no difference, except that desire is generally related to men insofar as they are conscious of their appetite. So desire can be defined as appetite together with consciousness of the appetite."

${ }^{20}$ The role of unnoticed factors in causing our volitions and actions has been the subject of recent studies in psychology and philosophy of psychology. Thus, in a recent survey of literature, Joshua Shepherd writes: "Work on the role of unnoticed situational factors has been taken to show that the commonsense understanding of action, on which we asses and decide to act on the basis of consciously recognized reasons is misleading. In fact, many of the features that move us to act do so via non-conscious, reason-irrelevant processes" ("Scientific Challenges," 200).

${ }^{2 \mathrm{I}}$ In the last sentence, Spinoza seems to claim that the common perception of the will as the causal source of our actions is a Chimera, i.e., a mere verbal being that is not accompanied by any idea, not even an idea of the imagination. For the distinction between Chimeras and Beings of Reason (e.g., universals), see CM I I (I/233/23-35) and CM I 3 (I/24I/8-I6). This claim is distinct from - though not necessarily inconsistent with - Spinoza's assertion in E2p48s that the will (just like all other mental faculties) is a mere universal. Presumably, whether the will is a Chimera or a universal depends on how one understands this term. 
According to Spinoza, the mental mechanism that generates our belief in free will is the following. When we act (or have a desire that leads us to $\mathrm{act}^{22}$ ), we are normally aware of our action or desire, but have only very limited knowledge of the causes of our action or desire. The data we have about why we act, or desire a certain action, is almost always incomplete, in the sense that we do not see the known causes as necessitating the specific course of action or desire. Sometimes, in order to understand some of our actions or desires, we go to a psychoanalyst and spend hundreds of hours in an attempt to explain fully one of our decisions or actions. Such concentrated investigations aimed to achieve full transparency in our desires and actions may or may not be successful. Yet we make thousands of such decisions or actions every day, and in virtually all of these decisions there is major explanatory gap between what we know about the causes of our actions and the choice to pursue a certain action. In almost all of these cases, our knowledge about the causes of our actions provides a constraint about what we may choose, but hardly ever is this knowledge so comprehensive that we perceive it as strictly necessitating a specific action or desire.

At this point, Spinoza comes out and asks how we phenomenologically experience the explanatory gap between what we know about the causes constraining our actions (or desires) and the actions (or desires) that actually transpire. Since our knowledge of the causes of our actions (or desires) hardly ever necessitates the action (or desire), we phenomenologically experience the action (or desire) as free and not necessitated.

Consider, for example, my moving my right hand upward. I know quite a bit about the causes of this event insofar as I know much about my hands and their dispositions, and I also know that my intention was to demonstrate by this act the aforementioned explanatory gap. ${ }^{23}$ Yet I could just as well demonstrate the same point by moving my left hand or by moving my right hand downward. Why, then, did I move it upward? In spite of my very intimate "familiarity" - if this is the right word - with my right hand, it is hard for me to come up with an answer (obviously I have many

22 The current passage focuses on the action, while the passage from Eiapp concentrates on the volition that leads us to the action. Of course, for Spinoza, mental items (such as volitions) cannot interact with physical items. For the causal barrier between modes of different attributes, see E2p6.

${ }^{23}$ I my daily experience, I experience the intention as the cause of my action. Spinoza would, obviously, reject any causal interaction between mental and physical items. Instead, he would argue that it was the physical parallel of my intention that contributed to the causation of the physical action. The example just cited attempts to capture merely the phenomenological experience. 
conjectures, but I would need to work very, very hard in order to achieve, if indeed I ever could, full cognitive transparency regarding the causal trajectory that determined the specific movement of my right hand).

The explanatory gap between my limited knowledge of the reasons for my actions (or desires) and the complete knowledge of the causal trajectory that determines my actions creates, by necessity, the phenomenological experience of free volitions (i.e., volitions that are not necessitated). This experience of free volitions accompanies us in every single moment in our lives, ${ }^{24}$ and thus the belief in free will is constantly reinforced to a degree that it can hardly be shaken.

I mentioned earlier that the three elements that conspire to generate the belief in free will are each necessary ${ }^{25}$ and jointly sufficient conditions for the formation of this belief. Let us now look closely at each element.

(I) Were we not to have appetites and volitions, we would not form the belief in free will even if we were self-conscious and ignorant of most causes of our actions, since in the absence of volitions, we would have no ideas of any volitions. (2) Were we to have volitions without consciousness of these volitions, we would not form beliefs about these volitions since we would not be aware of them. If having volition without consciousness does not suffice to form the belief that we have volitions, clearly it should not suffice to form the belief that we have free volitions. (3) Suppose we had volitions, and were conscious of them, and yet we were equally conscious of all the causes of our volitions. Our experience of the world would not suffer from the aforementioned explanatory gap. In such a scenario, we would experience our volitions as completely determined by their causes, just as we would experience the movement of our body in an elevator. In both cases, we would have a strict deterministic explanation for the changes in the states of our minds or bodies, and this strict deterministic explanation of our volitions would not allow the formation of the belief in free will for two reasons. First, the belief in free will would be strictly ruled out insofar as our experience - i.e., strict deterministic causation of the will - will

${ }^{24}$ For Spinoza, every idea has a conative (or volitional) state built into it (see Della Rocca, "Power of an Idea," 2II-2I3). Thus, whenever we have ideas, we have volitions.

${ }^{25}$ By claiming that each element is necessary for the formation of the belief in free will I mean only that these elements are necessary for the causal trajectory Spinoza identified as necessitating the belief in free will. Of course, one can suggest alternatives trajectories leading to the belief in free will (and these may, or may not, include elements I-3). To the best of my knowledge, in his late works Spinoza does not consider such alternative trajectories (and obviously does not prove that such trajectories are impossible). He simply claims to be suggesting the best explanation of the phenomenon at stake (i.e., the ubiquity of the belief in free will in spite of its obvious falsity). 
falsify the belief in free (i.e., unnecessitated) will. Second, the belief in free will would be redundant, as it would not be needed in order to explain our volitions.

It is thus only the contriving of all three elements - volitions, awareness of the volitions, and ignorance of the causes of our volitions (or the explanatory gap) - that together explain the etiology of our belief in free will.

The passage in E2p35s stresses one further point in Spinoza's account of why we form the belief in free will. The constant and ubiquitous experience of our volitions as uncaused becomes ingrained in the nature of our minds. Yet, we may still (rightly!) ask why we have these "free" volitions. Given the consistent absence of such explanation, claims Spinoza, we assume the existence of an entity - the Will, or the faculty of volition - which is taken to be the ultimate and uncaused source of our volitions. For Spinoza, "the Will" is a black box that explains nothing. We know nothing about its mechanisms, and the very idea of its having causal influence over bodies is unintelligible, since volitions qua mental items have no common measure with our body, ${ }^{26}$ and we have no way to explain the very possibility of such causal interaction. Thus, Spinoza concludes: "For all are ignorant of what the will is, and how it moves the Body; those who boast of something else, who feign seats and dwelling places of the soul, usually provoke either ridicule or disgust" (E2p35s). ${ }^{27}$

The Ethics is a book that truly aims at elucidating the nature of human beings and their blessedness. For that reason, Spinoza's few remarks about the mental life of animals are nothing more than occasional digressions whose aim is the elucidation of the nature of the mental in general. There is good textual evidence showing that Spinoza held that animals enjoy a certain degree of consciousness, though this is not the place to discuss this

${ }^{26}$ Addressing Descartes' claim that the pineal gland is the locus of the interaction between mind and body, Spinoza writes sardonically: "I should like very much to know how many degrees of motion the Mind can give to that pineal gland, and how great a force is required to hold it in suspense. ... And of course, since there is no common measure between the will and motion, there is also no comparison between the power, or forces, of the Mind and those of the Body. Consequently, the forces of the Body cannot in any way be determined by those of the Mind" (Espref | II/280/4-I6. Italics added.).

${ }^{27}$ Cf. E3p2s: "Again, no one knows how, or by what means, the Mind moves the body, nor how many degrees of motion it can give the body, nor with what speed it can move it. So it follows that when men say that this or that action of the Body arises from the Mind, which has dominion over the Body, they do not know what they are saying, and they do nothing but confess, in fine-sounding words, that they are ignorant of the true cause of that action.” 
issue. ${ }^{28}$ Still, assuming that Spinoza ascribes consciousness to nonhuman animals, it seems he would also assert that animals experience, just as we do, their actions as free volitions. Clearly animals have strivings/volitions, and clearly animals are ignorant of the causes of their volitions. If we add to this that animals are conscious of their volitions, then the mechanism that generates the belief in free will is already in place. I am not aware of any text in which Spinoza discusses the free will of animals, but in a fascinating letter dated October 1674, Spinoza provides a detailed analysis of the free will of a moving stone. He begins his discussion by noting:

What I say here about the stone must be understood concerning any singular thing, however composite it is conceived to be, ${ }^{29}$ and however capable of doing many things: ${ }^{30}$ each thing is necessarily determined by some external cause to exist and produce effects in a fixed and determinate way.

Next, conceive now, if you will [si placet], that while the stone continues to move, it thinks [cogitare], and knows [scire] that as far as it can, it strives to continue moving. Of course, since the stone is conscious only of its striving, and not at all indifferent, it will believe that it is very free, and that it perseveres in motion for no other cause than because it wills to. This is that famous human freedom everyone brags of having, which consists only in this: that men are conscious of their appetite and ignorant of the causes by which they are determined. So the infant believes that he freely wants the milk; the angry boy that he wants vengeance; and the timid, flight. Again, the drunk believes it is from a free decision of the mind that he says those things which afterward, when sober, he wishes he had not said. Similarly,

${ }^{28}$ See E2pi3s (II/96/26-29): "[T] he things we have shown so far are completely general and do not pertain more to man than to other Individuals, all of which, though in different degrees, are nevertheless animate. For of each thing there is necessarily an idea in God, of which God is the cause in the same way as he is of the idea of the human Body. And so, whatever we have said of the idea of the human Body must also be said of the idea of any thing" (Italics added. See also Spinoza's similar claims in Ep. 58). The last two sentences commit Spinoza to the view that every entity has a parallel idea or mind (see Melamed, Spinoza's Metaphysics, I70-17I). In E2pp22-23, Spinoza asserts that the mind knows itself by having second-order ideas. E2p3 together with E2p7 commits Spinoza to the view that the order of higher-order ideas is isomorphic with the order of first-order ideas. Thus, it is not only that tables and rocks have minds, but they are also endowed with some degree of cognition of their minds (see Melamed, Spinoza's Metaphysics, 175). For a more detailed discussion of Spinoza's panpsychism, see my "Spinoza's Anti-humanism," I6I-I63.

29 For Spinoza, the degree of complexity of a certain body is a feature paralleling the degree of "animation" of the mind of that body. See E2pi3s | II/96/26-28.

${ }^{30} \mathrm{Cf}$. E2pi3s | II/97/4-IO: "And so to determine what is the difference between the human Mind and the others, and how it surpasses them, it is necessary for us, as we have said, to know the nature of its object, i.e., of the human Body. I cannot explain this here, nor is that necessary for the things I wish to demonstrate. Nevertheless, I say this in general, that in proportion as a Body is more capable than others of doing many things at once, or being acted on in many ways at once, so its Mind is more capable than others of perceiving many things at once." Italics added. 
the madman, the chatterbox, and a great many people of this kind believe that they act from a free decision of the mind, and that they are not set in motion by an impulse. ${ }^{3 \mathrm{I}}$

The passage presents Spinoza's analysis of the etiology of our belief in free will, which should be familiar to us by now. Spinoza provides several illustrations of cases in which humans act due to impulses whose strict deterministic causes are relatively transparent to us (though not to the agents - such as the hungry infant - who experience their desires as free volitions). Does Spinoza truly think that the stone "thinks [cogitare], and knows [scire] that as far as it can, it strives to continue moving"? Scientia is a term Spinoza normally reserves for adequate and advanced knowledge, and thus we might read this line more as a thought experiment than as a genuine assertion that the stone knows its striving. Still, given Spinoza's preface to the discussion of the stone case - "What I say here about the stone must be understood concerning any singular thing, however composite it is conceived to be" - I tend to consider the stone example as illustrating a universal principle that applies to all singular things insofar as they are singular things. ${ }^{32}$

Immediately following the passage just quoted, Spinoza makes a claim that does not appear in the other texts we have studied so far: he argues that our belief in free will is in some sense "innate."

And because this prejudice is innate in all men [Et quia hoc praejuidicium omnibus hominibus innatum est], they are not easily freed of it. ${ }^{33}$

What does Spinoza mean by the claim that the prejudice/belief in free will is "innate in all men"? If I understand Spinoza correctly, he does not suggest that we are born with an "innate idea" of free will, ${ }^{34}$ since such a claim would make redundant his entire analysis of how and why we form the belief in free will. Instead, what Spinoza seems to be asserting here is that it is a universal human condition that we are born as beings who are striving (i.e., having volition), conscious of our striving, and ignorant of the causes of our striving. In other words, we are born into a condition that necessarily excites the mechanism generating the belief in free will.

${ }^{31}$ Ep. $58 \mid$ IV/266/7-25. The last two sentences of this passage appear verbatim in E3p2s | II/I43/24-29.

32 The stone might have adequate (yet primitive) knowledge of the attributes, since the attributes cannot be conceived inadequately, for Spinoza, insofar as the conditions for error do not obtain in their case. In other words, if the attributes are conceived, they must be conceived adequately. This is not, however, the proper place to investigate this intriguing issue in detail.

${ }_{33}$ Ep. 58 | IV/266/25-26. Italics added.

34 Descartes counts the belief in free will as an innate idea and common notion. See Principles of Philosophy, I 39. 
Notice that in the last passage Spinoza asserts that "men are not easily freed" from the belief in free will. Prima facie, this claim seems to imply that with some, perhaps much, effort, men can be freed from the illusion of free will. We will address this question toward the end of this chapter.

\section{Part III: Can We Avoid the Illusion of Free Will?}

In the previous section, we examined closely the three elements that contrive to produce the false belief in free will, according to Spinoza. But is it indeed the case that whenever these three elements obtain, the belief in free will is necessarily produced? This question is especially urgent for Spinoza since he is strongly committed to the key doctrine of the conatus, according to which "each thing, as far as it can by its own power, strives to persevere in its being [Unaquaeque res, quantum in se est, in suo esse perseverare conatur]" (E3p6). For Spinoza, striving, willing, and having an appetite are virtually the same: "When this striving is related only to the Mind, it is called Will; but when it is related to the Mind and Body together, it is called Appetite" (E3p9s). Since Spinoza is also committed to panpsychism - i.e., the view that all bodies are animated and have parallel ideas that are their minds $s^{35}-$ it is clear that he must ascribe some degree of volition and appetite to all things, rocks and tables included. The question then arises: why don't I ascribe free will to the table? Insofar as (I) the table is striving to persevere in its being, (2) I know that the table is striving, and (3) I do not know most of the causes of the table's striving, it would seem that per Spinoza's analysis of the causes of our belief in free will, we must ascribe free will to the table. Yet we do not.

A possible first line of defense on the side of the Spinozist would be to suggest that in our daily experience, we consider the states of (what we consider to be) inanimate objects - such as rocks and tables - to be fully determined by their causes, and thus, unlike the case of human action, we do not experience the explanatory gap between what we know about the causes of the table's "action," or movement, and the course of movement/ action that actually takes place. Since the explanatory gap is one of the three elements that are necessary for the formation of the belief in free will, the absence of this gap explains why we do not ascribe free will to the table and other, so-called inanimate objects.

35 See E2pi3s | II/96/26-32 and the previous section. In "Spinoza on Death," Oded Schechter and I provide a detailed defense of Spinoza's panpsychism relying on his rejection of emergent qualities. 
This Spinozist response is helpful, yet not fully satisfying. Let us consider a case in which we observe a table moving suddenly without knowing the causes of its movement. We would obviously wonder at the event taking place before our eyes, but in all likelihood, we would not ascribe free will to the table. Instead we would consider numerous alternative explanations for the surprising movement of the table (e.g., perhaps there is metal in the table and a powerful magnet is attracting it, or alternatively, perhaps the table is pulled by a transparent wire). ${ }^{36}$

At this point, the Spinozist may launch a second line of defense arguing that it is only introspective consciousness [conscientia] of our own volitions and actions that brings about our belief in free will, while other kinds of knowledge of the striving of things will not result in the attribution of free will to those things. In other words, my consciousness of my own volitions is an intimate and unique kind of cognition, and it is only this kind of cognition that excites the deep psychological mechanism that generates the belief in free will. This line of defense would fail for at least two reasons. First, Spinoza's thoroughgoing rationalism should not allow him to be satisfied merely by the declaration that "introspective consciousness" is a special kind of cognition, and that only this kind of cognition may excite the belief in free will. If this line of defense is to have any value, it must first show why the nature of the cognition at stake (introspective consciousness as opposed to other kinds of cognition) makes a difference with regard to the formation of the belief in free will. Second, we normally ascribe free will to other human beings though we have no introspective consciousness of their volitions. Thus, the kind of cognition that excites the belief in free will cannot be restricted to introspective consciousness. Though we have just rejected this second line of defense, the last observation seems to point in the direction of a satisfactory Spinozist rebuttal.

We have just asserted that in normal circumstances we would ascribe free will to other human beings - but not to tables - though in both cases we have no introspective consciousness of any volitions/appetites occurring in the humans or tables at stake. Would we normally ascribe free will to chimpanzees? Biologists and laypeople are likely to come up with different answers to the last question, but it seems fair to say that the more the entity

36 The Spinozist may also respond to the last argument by claiming that were we to observe the table moving frequently enough and in a manner that could be explained as an intentional decision (e.g., if the table were to move whenever a saw appeared in its vicinity), we would ascribe free will to the table. In fact, many animation films follow precisely this very pattern. 
at stake is like us, the more likely we are to ascribe free will to it. But why is this so?

Spinoza has a ready explanation for this phenomenon: we tend to ascribe similar affects (such as desire) to things we deem to be like us. This is Spinoza's doctrine of the imitation of the affects (E3p27). In Part III of the Ethics, Spinoza employs this doctrine to explain primarily sympathy and pity, and this deep psychological mechanism also plays an important role in the foundation of Spinoza's political theory. ${ }^{37}$ In E3p27s, Spinoza discusses explicitly Emulation [aemulatio], the imitation of the desires of other beings. Here too Spinoza stresses that the imitation mechanism is excited only with regard to a thing we deem "like us." Now we can spell out Spinoza's intriguing answer to our original question: why do we not ascribe free will to tables?

We do not ascribe free will to tables because we do not ascribe volitions and appetites to tables, and we do not ascribe volitions and appetites to tables because we deem them totally unlike us. We normally consider ourselves as separate islands of mental life within the ocean of inanimate nature. Spinoza rejects this view. To be sure, he would agree that we are very different from tables and rocks (we are far more complicated and capable entities), yet he would argue that when we assume an abyss between us and the rest of nature, we exaggerate this difference. This perception of ourselves as being totally unlike the rest of nature is part of our normal folk psychology and is deeply ingrained in our minds. As a result, our psychological mechanisms would be less likely to ascribe volitions and appetites to other entities to the extent that we consider these entities unlike us.

Having responded to the objection presented at the beginning of this section, let us turn now to another intriguing criticism of Spinoza's analysis of the causes of our belief in free will.

In his 1797 Second introduction to the Wissenschaftslehre, Fichte praises Spinoza as "one of the greatest thinkers of the modern age" and then turns to refute Spinoza's rejection of free will:

Spinoza could not have been convinced of his own philosophy. He could only have thought of it; he could not have believed it. For this is a philosophy that directly contradicts those convictions that Spinoza must necessarily

37 See TP Ch. I | III/275. For instructive discussions of the imitation of affects in Spinoza, see Della Rocca, "Spinoza's Metaphysical Psychology," 247-25I, and Steinberg, "Imitation, Representation, and Humanity." I am also indebted to Michael Della Rocca for a very helpful discussion of this issue. 
have adopted in his everyday life, by virtue of which he had to consider himself to be free and self-sufficient. ... He was convinced that a purely objective mode of thinking [Raisonnement] must necessarily lead to his system, and he was right about this. But in the course of his thoughts it never occurred to him to reflect upon his own act of thinking; this is where he went astray, and this is how came to place his speculations in contradiction with his life. ${ }^{38}$

Fichte's presentation of Spinoza's views on free will is mostly adequate. He might have slightly radicalized Spinoza's claim that men "are not easily freed" from the belief in free will ${ }^{39}$ by ascribing to Spinoza the stronger view that we cannot avoid the belief in free will - this is presumably the meaning of Fichte's claim that "Spinoza could not have believed" his own claims about free will - yet, overall, Fichte's presentation of the Spinozist position is fair and penetrating. But what did Fichte mean by claiming "it never occurred to Spinoza to reflect upon his own thinking"?

In a fine recent study, Allen Wood has attempted to explain Fichte's critique of Spinoza. Wood presses two closely related points in Fichte's name. First, he argues:

Often we are aware of the circumstances that ground our desires, but when we regard these circumstances as reasons for those desires, we cannot coherently represent them as necessitating causes that make any choice impossible. The Fichtean explanation for our conviction that our free actions are uncaused is based on precisely this point: that we fall into incoherence if we try to represent what we do for reasons, including the acquisition of understanding or conviction, as causally necessitated. ${ }^{40}$

Wood's second point attempts to highlight the alleged incoherence of the necessitarian position from a slightly different angle:

No matter how good the arguments on the necessitarian side may be, they always arrive too late to admit the possibility of any rational conviction based on them. For in order even to entertain them as rational arguments, I must already represent myself as having a variety of possible judgments open to me, in order to be capable of deciding the question at a time and according to reason. ${ }^{4 \mathrm{I}}$

In response to the first point, Spinoza would most likely deny that "often we are aware of the circumstances that ground our desires," arguing instead

${ }^{38}$ Fichte, Fichtes Werke, I 513 | Fichte, Introductions, $98 . \quad 39$ Ep. 58 | IV/266/26.

40 Wood, "Fichte on Freedom," I34. Notice that I have reversed the order of Wood's presentation of the two points.

4I Wood, "Fichte on Freedom," I32. 
that it is very rare - if it is even possible - to have complete knowledge of all the causes of any given volition we have; but this is a minor point. How would Spinoza respond to Wood's (and Fichte's) claim that we cannot coherently represent our reasoning and choices as necessitated?

One strategy that Spinoza could pursue would be to address the issue first from a third-person perspective. Let's assume that I am observing my close friend, Felix. Can I represent Felix's reasoning and choices as completely necessitated by their causes? Obviously, I normally explain Felix's choices (and his reasoning) through the causes acting on him. It would seem that the more I know Felix and the causes acting on him, the more I am likely to see his choices and volitions as determined by these causes. ${ }^{42}$ Can I coherently represent Felix's choices as being necessitated by their causes? I see no reason why I could not. ${ }^{43}$ In fact, it would seem that such a representation would be just what I would expect to have in the extreme, limiting case of knowing all the causes acting on Felix.

Wood's argument, however, focuses on the first-person perspective, and as far I can see, the Spinozist would agree with the crux of his argument: there is indeed a strong tension, perhaps even incoherence, between our sturdy conviction that we freely deliberate between alternative courses of actions - which we represent as possible ${ }^{44}-$ and the necessitarian view, which the Spinozist contends is the unavoidable conclusion of a consistent metaphysics. But is it indeed the case that given such conflict, our libertarian convictions should have the upper hand, since the necessitarian argument "arrives always too late"?

In order to address the latter question, let us consider the case of Benedictus, a patient suffering from a mild-to-moderate form of ObsessiveCompulsive Disorder (henceforth, OCD). The most recent edition of the American Psychiatric Association's Diagnostic and Statistical Manual of Mental Disorders defines this condition as follows:

Obsessions are recurrent and persistent thoughts, urges, or images that are experienced as intrusive and unwanted, whereas compulsions are repetitive

${ }^{42}$ For Spinoza, the essence of Felix will be one of the causes determining any of the states of Felix, his volitions included (see E2pi3sAı"). Furthermore, Spinoza would consider Felix more free the more his actions (and volitions) can be explained through his essence, and not through external causes (see Sleight, Chapelle, and Della Rocca, "Determinism and Human Freedom," I23I).

${ }^{43}$ Cf. Nagel, View from Nowhere, no.

44 For Spinoza's definition of possibility in terms of one's lack of knowledge of the causes that are necessary to produce a thing, see $\mathrm{E}_{4} \mathrm{~d}_{4}$. Cf. TIE $\$ 53$. 
behaviors or mental acts that an individual feels driven to perform in response to an obsession or according to rules that must be applied rigidly. ${ }^{45}$

Whenever Benedictus leaves his home, he repeatedly checks that the entrance door is properly locked. Every departure from his home involves a ritual in which he compulsively checks the door twenty or thirty times, and obsessively thinks about the possibility that he might have left the door unlocked. Benedictus has gone to a therapist, and was unmistakably diagnosed as suffering from OCD. To accept such a diagnosis is really to represent one's own patterns of thoughts as determined by strict psycho-physiological mechanisms that compromise, if not fully annul, one's free will. ${ }^{46}$ Yet, if we approach Benedictus a second before he checks the door lock (for the twentieth time) and ask whether he can choose not to check the door, he would respond positively. ${ }^{47} \mathrm{He}$ is fully aware of his diagnosis, and yet he also knows that if he does not check the lock again, there is some chance he would leave the house unlocked. Indeed, if we use Wood's formulation, Benedictus "represents himself as having a variety of possible judgments open to him." There is clear conflict between Benedictus' representation of himself as having a choice between different courses of action, and the acceptance of the OCD diagnosis that explains his behavior as a rigid mechanistic psychological pattern.

Should Benedictus' representation of himself as having a choice between different courses of action make him reject the OCD diagnosis insofar as it is incompatible with his representation of himself as a freely deliberating agent? I think he should not. Benedictus is much more likely to have better quality of life if he accepts the diagnosis and tries to treat it adequately, but this utilitarian consideration is really the least important issue. More significantly, it would seem that in the current scenario rejecting the OCD diagnosis due to its incompatibility with our deep conviction that we are freely deliberating agents would amount to nothing short of choosing to live under an illusion.

45 DSM-5, 235.

${ }^{46}$ For the apparent contrast between acceptance of the diagnosis of OCD and the (simultaneous) positing of free will, see Churchland, Brain-Wise, 208; Strawson, "Impossibility of Moral Responsibility," 222; and Meynen, "OCD, Free Will, and Control," 326-328. D.A. Levy describes OCD as a "malady of free will" ("Neural Holism and Free Will," 2I4).

47 Describing a similar case, Meynen writes: "She is, in her own words, almost completely in control with respect to the cleaning of the house" ("OCD, Free Will, and Control," 328). Dr. Zoran Vukadinovic pointed out to me that addiction also involves the illusion of free choice. 
Along the same lines, Spinoza would argue, rejecting necessitarianism just because it conflicts with our deeply ingrained self-perception as freely deliberating agents would be to engage in a similar act of self-deception (assuming necessitarianism is, otherwise, well-motivated). ${ }^{48}$

\section{Conclusion}

In this chapter, we have studied Spinoza's explanation for our conviction that we are freely acting agents. We have seen that, according to Spinoza, the belief in free will is innate and very hard to eradicate. Spinoza thinks that by recognizing the necessity of things, we can lessen the grip of the passions on our minds. ${ }^{49}$ Thus, recognizing the necessity of things has a certain therapeutic value. This said, I tend to think Fichte was right in ascribing to Spinoza the view that we can never liberate ourselves from the belief in free will. The psychological mechanism that elicits our belief in free will accompanies us at every moment of our lives, and such a ubiquitous psychological mechanism seems impossible to dismantle. In this regard, our feeling of freedom is not unlike other illusions of the imaginations. Just as we do not stop imagining the sun to be very close to us when we learn its true distance, so, it seems, we do not stop perceiving ourselves as acting out of free will even when we learn that the will is never free. ${ }^{50}$

Spinoza's view of the belief in free will as innate yet false cognition raises several intriguing epistemological issues. ${ }^{5 \mathrm{I}}$ Recall that, for Descartes, innate cognitions, which we cannot resist asserting must be true, since otherwise

${ }^{48}$ Notice that my Benedictus case is just an updated variation on Spinoza's discussion in Ep. 58 of "the infant that believes that he freely wants the milk, the angry boy that wants vengeance, and ... the drunk who believes it is from a free decision of the mind that he says those things which afterward, when sober, he wishes he had not said."

49 See E5p6: "Insofar as the Mind understands all things as necessary, it has a greater power over the affects, or is less acted on by them."

so See E2p35s. Cf. Barry, "Spinoza and the Feeling of Freedom." Yet the analogy with the case of our perception of the sun is somewhat incomplete since in the case of our perception of the sun we are readily convinced about its true distance once we learn it, while in the case of our belief in free will it is extremely hard for us to counter this persistent illusion due to its deep grounding in the conditions of human action. One place where Spinoza seems to assert that it is hardly possible for us to internalize and act according to the truth of necessitarianism is Letter 43: "Whether we do what we do necessarily or freely, we are still led by hope and fear" (IV/223/I8-I9).

5I Another epistemological issue, unrelated to innateness, is whether Spinoza's view on free will is an instance of Moore's Paradox (i.e., whether we should ascribe to Spinoza the assertion: "Necessitarianism is true, but I do not believe it"). This question cannot be adequately addressed here. 
God, who created us in such a condition, would be a deceiver. ${ }^{52}$ For Spinoza, such an argument has little force; God may well be a deceiver, ${ }^{53}$ since Spinoza's God has no concepts of good and evil. ${ }^{54}$

Some current philosophers consider freedom of the will an undeniable fact. ${ }^{55}$ The so-called intuitive appeal of the belief in free will is pretty strong. ${ }^{56}$ Remarkably, Spinoza has a powerful explanation of why we have such a strong conviction. By providing an elegant explanation for this most common "intuition" Spinoza pulls the rug out from under the legs of the proponents of free will. Thus, the real import of Spinoza's discussion of free will lies not in showing that freedom (qua uncaused action) and determinism are incompatible - a fairly trivial claim - but in providing a simple and refined explanation for one of our most deep-seated, and yet, false, beliefs.

52 See Descartes' Meditations, AT VII 79-80 | CSM 2 55-56. 53 See TTP, chapter 2 | III/3I.

54 See E4p68d: "I call him free who is led by reason alone." Since God is free and "is led by reason alone," he cannot have concepts of evil (by E4p64) and good.

ss See, e.g., Van Inwagen's categorical assertion: "free will undeniably exists" ("Free Will Remains a Mystery," I58). Addressing necessitarianism, Van Inwagen describes this position as simply "absurd" (Essay on Free Will, 202).

56 See Nahmias, "Close Calls," 627-628. 